\title{
Southern Hemisphere Observations
}

\author{
Wayne Orchiston \\ Anglo-Australian Observatory, PO Box 296, Epping, N.S.W. 2121, \\ Australia. wo@aaoepp.aao.gov. au
}

\begin{abstract}
Because of insurmountable problems associated with absolute dating, the non-literate cultures of the Southern Hemisphere can contribute little to Applied Historical Astronomy, although Maori traditions document a possible supernova dating to the period 1000-1770AD. In contrast, the abundant nineteenth century solar, planetary, cometary and stellar observational data provided by Southern Hemisphere professional and amateur observatories can serve as an invaluable mine of information for present-day astronomers seeking to incorporate historical data in their investigations.
\end{abstract}

\section{Introduction}

The Southern Hemisphere lies south of the Equator and includes the following land masses: Southern Africa (3.5 My), Indonesia (2.5 My), Australia (70 ky), New Zealand (1 ky) and South America (?15 ky). These are listed in order of longitude east from Greenwich, and their earliest approximate dates of human occupation are included in parentheses.

While the Southern Hemisphere has been inhabited for a much longer timerange than the Northern Hemisphere, this is a serious drawback since until comparatively recently all human cultures there were non-literate. Thus, our understanding of indigenous astronomical traditions must be based upon data derived from myths and traditions, rock art, decorated artifacts and the orientation and design of houses and other structures. These typically present problems of absolute dating for the archaeologist and interpretation for the astronomical historian.

Under these circumstances, can the Southern Hemisphere make any meaningful contribution to Applied Historical Astronomy? I believe that it can, but only in a very limited way for the pre-telescopic era. However, when we consider data from the nineteenth and early twentieth centuries, during the telescopic era, we are on much firmer ground.

\section{The Pre-telescopic Period}

One of the key problems in trying to relate pre-telescopic Southern Hemisphere astronomical data to contemporary astronomy is absolute dating, and with such long chronologies represented in all regions except New Zealand, it makes most sense to focus on Maori Astronomy. New Zealand was first settled by ancestral 
Polynesians about 1,000 years ago (Sutton 1992), so any Maori astronomical traditions that are not represented in Central and East Polynesian astronomical accounts most likely date to the last millennium. This is particularly apposite when searching for evidence of specific novae, supernovae, solar eclipses or comets.

Apart from the chronological issue, another advantage of selecting this particular region for a case study is that a published account of Maori astronomy already exists (Best 1922), and furthermore, given its far southern latitude (from $34^{\circ}$ to $47^{\circ} .5$ ), Maori astronomers were able to view parts of the sky that were generally beyond the range of those astronomically-aware cultures of Asia and the Middle East.

Upon reviewing Maori astronomy (Orchiston 2000), I was able to locate a reference to a possible supernova. Best (1922: 46) refers to Mahutonga, which is "... a star of the south that remains invisible." Other terms including "Mahu" or " $m a h u$ " allow us to identify the general region of Crux as the original location of Mahutonga, and more specifically an error box extending in R.A. from $11 \mathrm{~h}$ $30 \mathrm{~m}$ to $14 \mathrm{~h}$ and in declination from $50^{\circ}$ to $70^{\circ} \mathrm{S}$. Since Mahutonga does not occur in Polynesian astronomical traditions its appearance (and disappearance) can be associated with the last 1000 years. Currently David Green (University of Cambridge) and I are scouring the Crux region for suitable supernova remnants.

Maori astronomical traditions also contain reference to what can only be described as a prehistoric meteorite impact. The term Rongomai denotes a fireball, and

At Owhiro, near Island Bay [Wellington], is a place named Te Hapua o Rongomai, where [Rongomai] ... is said to have descended to earth in past times. (Best 1922: 67)

There is also an account of a meteorite impact dating to the early years of European settlement:

... when the Pakakutu $p a$ [fortified settlement] at Otaki was being besieged [during the 1830s] Rongomai was seen in broad daylight, a fiery form rushing through space. It struck the ground and caused dust to rise. (ibid.).

\section{The Telescopic Era}

During the nineteenth and early twentieth centuries many Southern Hemisphere amateur and professional observatories were able to make a meaningful contribution to positional and descriptive astronomy, and the most significant of these are listed in Table 1, below.

These institutions were furnished with instruments that were, for the most part, modest by world standards but they were put to good use, and observatory publications and the pages of the Astronomical Register, Astronomische Nachrichten, Monthly Notices of the Royal Astronomical Society and towards the end of the century the Journal of the British Astronomical Association are peppered with papers presenting a southern hemisphere perspective.

These reports span sunspots, transits of Mercury and Venus, solar and lunar eclipses, lunar occultations of stars and planets, planetary features, phenomena 
Table 1. Significant professional (p) and amateur (a) observatories founded during the nineteenth century (after Evans 1988).

\begin{tabular}{llll}
\hline Country & Name & $\begin{array}{l}\text { Founding } \\
\text { Year }\end{array}$ & $\begin{array}{l}\text { Founding } \\
\text { Director }\end{array}$ \\
\hline South Africa & Royal, Cape of Good Hope (p) & 1828 & Fallows \\
& Feldhausen (a) & 1834 & Herschel \\
& Lovedale (a) & $1890 \mathrm{~s}$ & Roberts \\
Australia & Parramatta (a) & 1821 & Brisbane \\
& Williamstown/Melbourne (p) & 1853 & Ellery \\
& Abbott (a) & 1855 & Abbott \\
& Sydney (p) & 1858 & Scott \\
& Windsor (a) & 1863 & Tebbutt \\
& Adelaide (p) & 1874 & Todd \\
& Launceston (a) & 1878 & Biggs \\
New Zealand & Innes (a) & 1892 & Innes \\
Argentina & National, Córdoba (p) & 1884 & Grigg \\
& La Plata (p) & 1871 & Gould \\
Brazil & Rio de Janeiro (p) & 1882 & Beuf \\
Chile & National, Santiago (p) & 1827 & De Sauve \\
Peru & HCO's Boyden Station & 1852 & Modesta \\
\hline \hline
\end{tabular}

of Jupiter's and Saturn's satellites, comets, minor planets, double stars, variable stars, star colours and star positions. Collectively, they offer a wealth of data for the applied historical astronomer by providing long-running data sets on such things as sunspots, changing Jovian features, double star orbits, and variable star period and magnitude changes, all of which have theoretical or astrophysical implications.

These historic data also can aid in the interpretation of challenging recent observations. For example, it was only possible to explain the so-called "equatorial features" present in recent HST images of Eta Carinae by referring to the nineteenth century light-curve, and more specifically to the $\mathrm{S}$ Doradus-type outburst that occurred in 1890 and was documented by the Australian astronomers, Russell and Tebbutt, amongst others (see Morse, Humphreys, \& Damineli 1999).

On a quite different tack, Sekanina (1981) has analyzed historic observations of Comet 109P/Swift-Tuttle (1862) and used drawings of jets, envelopes and tail bands to establish that there were probably "...eight discrete emission areas, only one of which was demonstrably active throughout the nearly two months of physical observations." Comparable data for the period 1881 June-July exist for C/1881 K1 (Tebbutt), one of the unsung "Great Comets" of the nineteenth century (Orchiston 1999), and may warrant a similar investigation.

Finally, the International Astrographic (Carte du Ciel) Project has long been viewed as a millstone round the astronomical necks of many of the participating nations (see Lankford 1984), but Urban \& Corbin (1998) have recently shown that these earlier data can be used in conjunction with Hipparcos mea- 
sures to produce meaningful proper motions. In this regard, the contributions made by the Royal Observatory at the Cape of Good Hope in South Africa; Sydney, Melbourne and Perth Observatories in Australia; and the Argentine National Observatory in South America are invaluable.

\section{Concluding Remarks}

Although astronomical traditions of the non-literate indigenous cultures of the Southern Hemisphere offer little of relevance to applied historical astronomy (because, mainly, of the lack of chronological controls), data provided by nineteenth and early twentieth century professional and amateur observatories can make a useful contribution.

\section{References}

Best, E. 1922, The Astronomical Knowledge of the Maori (Wellington: Government Printer, Dominion Museum Monograph No. 3)

Evans, D.S. 1988, "Under Capricorn. A History of Southern Hemisphere Astronomy" (Bristol: Adam Hilger)

Lankford, J. 1984, "The impact of photography on astronomy", in The General History of Astronomy, Volume 4, Astrophysics and Twentieth-century Astronomy to 1950, Part A, ed. O. Gingerich (Cambridge: Cambridge University Press), 16-39

Morse, J.A., Humphreys, R.M., \& Damineli, A. (eds.) 1999, Eta Carinae at the Millennium (San Francisco: ASP Conference Series, Volume 179)

Orchiston, W. 1999, "C/1881 K1: a forgotten 'Great Comet' of the nineteenth century", Irish Astronomical Journal, 26, 33-44

Orchiston, W. 2000, "A Polynesian astronomical perspective: the Maori of New Zealand", in Astronomy Across Cultures. The History of Non-Western Astronomy, ed. H. Selin (Dordrecht: Kluwer), 161-196

Sekanina, Z. 1981, "Distribution and activity of discrete emission areas on the nucleus of periodic comet Swift-Tuttle", AJ, 86, 1741-1773

Sutton, D.G. (ed.) 1992, The Origins of the First New Zealanders (Auckland: Auckland University Press)

Urban, S.E., \& Corbin, T.E. 1998, "The Astrographic Catalogue. A century of work pays off", Sky and Telescope, 95(6), 40-44 